\title{
Earthquake Risk Assessment - Effect of a Seismic Event in a Moderate Seismic Area
}

\author{
O. Kegyes-Brassai ${ }^{1}$, R. P. Ray ${ }^{1}$ \\ ${ }^{1}$ Széchenyi István University, Dep. of Structural and Geotechnical Engineering, \\ Egyetem tér 1., 9026, Hungary \\ E-mail: kegyesbo@sze.hu, ray@sze.hu
}

\begin{abstract}
This paper presents the process of earthquake risk analysis from the probabilistic determination of seismic hazard and local site effects, through the evaluation of building vulnerability to an event resulting in seismic risk maps. These results can then serve as useful tools for decision makers and insurance companies, and can be applied directly to overall risk management plans of cities. Finally a case study for seismic risk assessment performed in city of Györ is presented, taking into account local site effects based on response analysis with more than 6000 realizations and rapid visual screening of 5000 building to obtain the seismic risk.
\end{abstract}

Keywords: earthquake hazard, local site effect, vulnerability, risk assessment

\section{Introduction: When the Earthquake Comes to Hungary}

Hungary is located in an interesting and active geological setting. The Alps and Carpathian mountain ranges give us winter skiing within a short distance. Thermal baths throughout the country are world-famous. The Danube and Tisa rivers make for pleasant travel and recreation sometimes, and are less pleasant other times. The Bakony Region and Lake Balaton are also unique places where one might enjoy the wonders of nature. Mixed into this geological melange is a moderate level of seismic activity. From a seismologist's view, it is not a question of "will there be and earthquake?" but rather "when will the next earthquake come?" Given the level of probability, it is the task of the civil engineer to devise ways to limit the harmful impact of such earthquakes on people. Generally this is what civil engineers do: try to make sense of the unpredictable and dangerous whims of nature while designing many of the building blocks of civilization. With earthquakes and seismic design, the separation between professional practice and public experience is great indeed. In Hungary, there is little, if any "collective memory" of earthquake hazards so the planning and execution of better design and construction practice relies on the efforts of engineers. Other hazards in Hungary, both natural (flooding) and man-made (Kolontár) are still within the public awareness. Earthquakes from 1810, seem like no more of a present threat than Napoleon's army. However, by a systematic method of quantifying the level of seismic hazard in a particular area, one may begin to assess the vulnerability of the surrounding built environment and determine the level of risk the general public faces with respect to economic damage, injury and death. Having a systematic method in place allows 
decision-makers (government agencies and the public) to better plan, prepare, and devote finite resources to reducing that risk.

\section{Earthquakes and Earthquake Damage}

Earthquakes and the damage they cause have been recorded throughout history. Ancient civilizations have recorded their occurrence and the havoc they wreak from China to Mesopotamia, to Egypt and Greece. The Carpathian region has witnessed its share of earthquakes as well; over 23000 recordable earthquakes have been found in historical records [22]. Most have been less spectacular events, causing misery to only an unfortunate few. However, what we do know about them is that they have been strong enough and frequent enough to take purposeful action in the design and construction of buildings, bridges, dams, levees, road and railroad embankments. Much of this action is reflected in modern building codes such as Eurocode, where an entire volume is devoted to special design considerations for seismic conditions.

In Hungary, the level of potential seismic shaking is moderate. Using the professional standard for seismic shaking, moment magnitudes can reach $\mathrm{Mw}$ 6.2. While this is not nearly as impressive as Mw 9.0 events that have occurred in Japan, Chile, Indonesia and Alaska, they are cause for concern. Examples of moderate events taking place in lessprepared built environments have resulted in genuine disasters, even the Northridge earthquake (1994) with a Mw 6.7 produced a Modified Mercalli Scale IX damage level and was the second costliest disaster in US [17, 19]. In each case, design and construction methods were not adequate for the anticipated earthquake. While perhaps not all the damage could have been prevented, a very large percentage should have gone undamaged. Learning from these events is a very valuable tool for the civil engineer. It presents in very clear terms what sorts of design and construction work and those that do not. This method of back-analysis has led to a great deal of cumulative expertise in the seismic design of structures.

\section{A Comprehensive Approach}

Seismic design of buildings, bridges, and other structures has evolved to the point where the engineer will take a comprehensive approach to the problem [3]. Defining the magnitude and location of possible seismic events, the general geology of the region, specific land and soil features, the general form of a structure, the materials from which it's made, even architectural details are considered during design. The approach for determining risk is divided into two parts: The seismic hazard (nature at its worst) and building resilience (the constructed environment). The interaction of these two parts may be complex (fig. 1.), but one can imagine that risk is greater when the hazard is strong and the resilience is weak. Since the magnitude and location of a seismic event varies greatly, probabilistic approaches are often used. Previously, engineers would estimate average seismic forces, and produce designs to withstand those forces, with an additional factor of safety added. This deterministic approach works if the designer has a very well-developed intuition about expected seismic forces, past experiments with similar events and structural behavior during earthquakes. A probabilistic approach attempts to quantify certainty (or uncertainty) in the entire design process. Designers can then estimate the level of safety in buildings as well as an estimate of how certain 
they are and have an understanding how sure they are in that estimate. The general public is less enthusiastic about such an approach. They would rather have reassurances and certainties where none exist. Communicating risk to the public then becomes very important, otherwise, misunderstandings can lead to bad feelings by all as witnessed before and after L'Aquila.

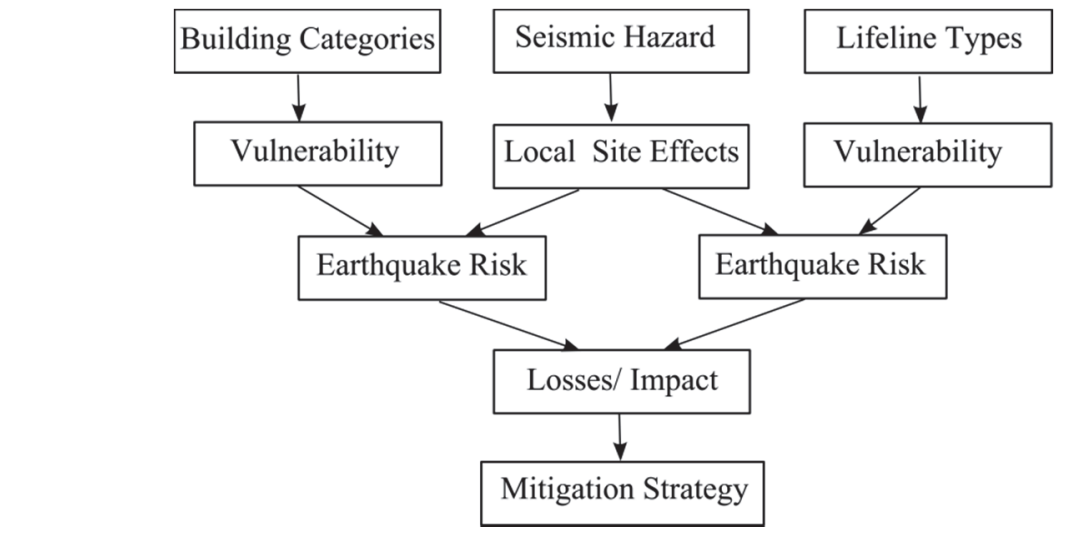

Figure 1. Seismic risk assessment for buildings (left side) and lifelines (right side) [15]

\section{Steps to Determine Earthquake Risk}

When designing for earthquakes, engineers must first consider how strong that earthquake might be. If we lived in Japan, that earthquake would be intense enough to throw our books off the shelf and destroy our house, if our home was in London it would hardly be enough to rattle our teacups. Hungary lies somewhere in between; in a moderate earthquake zone. In order to quantify the earthquake hazard, the seismic event is divided into segments of its journey to our "home" or building we are designing (fig. 2.). The main components are: 


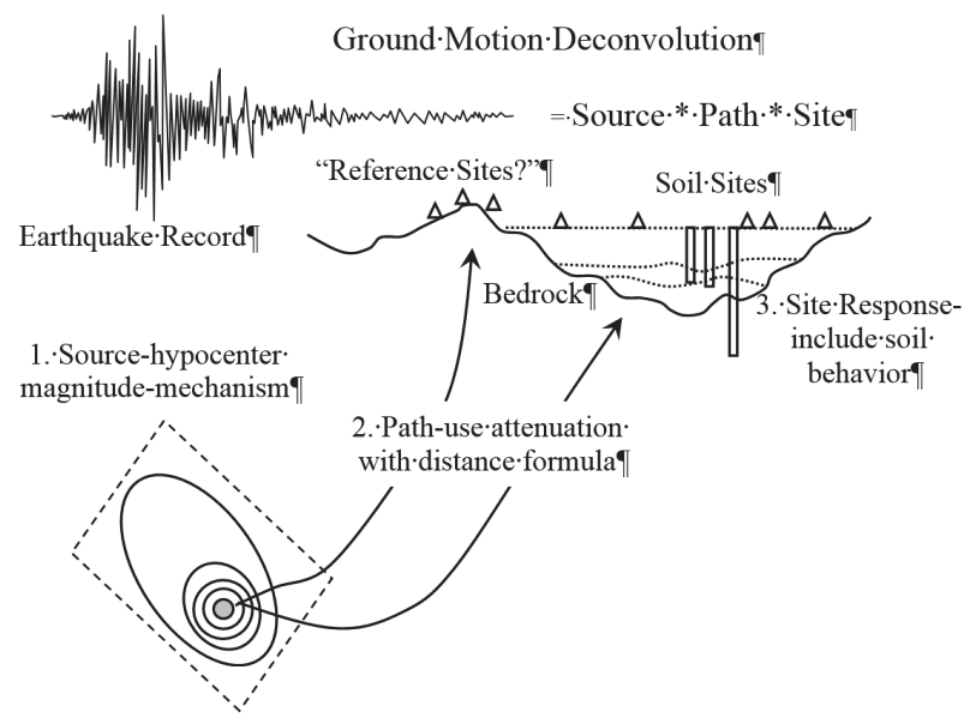

Figure 2. Path of earthquake shaking for seismic hazard assessment (adapted from Boore) [1]

1. Source location and magnitude, determined by the rupture itself.

2. Travel and attenuation through the rock which depends on the properties and layering of rock.

3. Travel and attenuation/amplification through the soils near our structure; the earthquake waves may be trapped, filtered, or amplified by the near-surface (upper $100 \mathrm{~m}$ ) soils.

\subsection{Earthquake Hazards}

Seismologists and engineers have a difficult time modeling the very specific source mechanisms. However, they can construct models that faithfully reproduce the location, energy release, and general wave characteristics of the source. Travel through rock layers is based on thousands of seismic records from around the world, and specifically the region of interest.

As they collect more data from different events, seismologists can develop better models to predict the magnitudes and frequencies of earthquake waves that will reach our site. Since local conditions have the greatest effect on our site, they must be considered with great care on a case by case basis. The lithology of local rock and soil above it can magnify earthquake waves many times over or transform them so that there is a predominant frequency of waves that arrive at the site. Naturally, if this frequency is just right (or just wrong) it may prove to be very dangerous to the stability of our structure.

Depending on the degree of refinement we require, we may use a variety of methods to determine the level of hazard at our site. Listing the possibilities from the simplest to most complex:

1. Use an acceleration coefficient (peak ground acceleration, PGA) obtained from 
seismic hazard maps and apply it to our static design as an added horizontal load.

2. Use a spectrum of coefficients than vary with frequency and apply the values the most closely match the fundamental frequency of the building.

3. Perform a site response analysis that uses an earthquake record applied to the bedrock in our site and scaled to the proper magnitude (PGA) to see what will happen at the surface.

4. Perform many site response analyses, with an entire family of earthquake records (10-100) and take the average surface response.

5. Determine the statistical distribution of magnitudes (1000's), locations and probability of occurrence of the source earthquake around your region. For each location determine the degree of attenuation of shaking when it reaches your site. Perform site response analysis using every one of these combinations for base input. Determine the statistical distribution of all site responses.

Option 5 is the basis for a probabilistic seismic hazard analysis PSHA. It is the standard analysis method used for critical sites [18]. The PSHA concept is shown in figure 3. Each source location has its own magnitude/recurrence relationship and depending on the geometry of the source location (fig. 3. shows point, line, and area geometries) there will be a spatial probability distribution as well. The distance between the source and the site will influence the level of attenuation of shaking in the rock underlying the site. Combining magnitude/recurrence probabilities and location/attenuation probabilities yields a broad distribution of probability vs magnitude of shaking at the site.

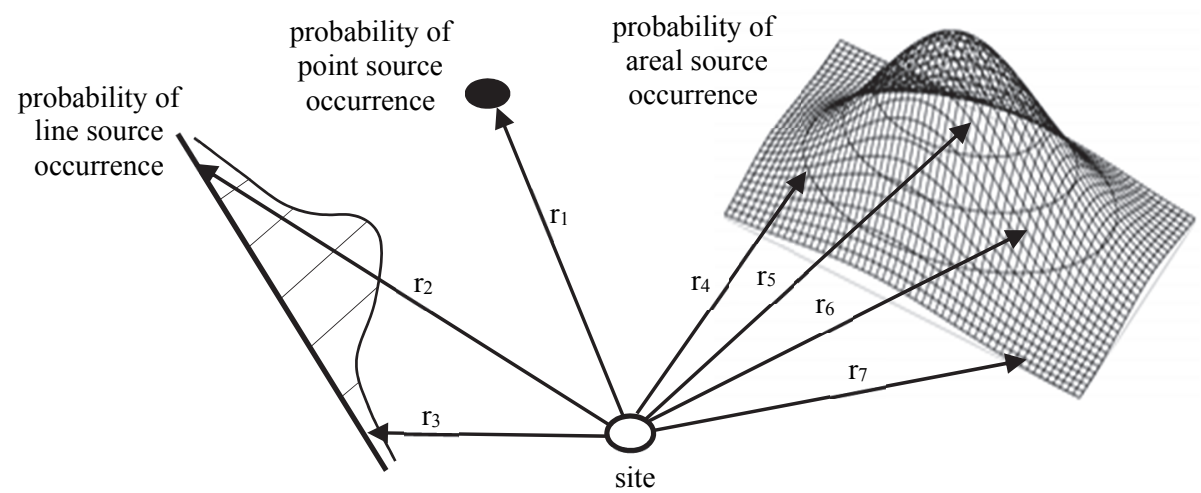

Figure 3. The location of an earthquake may be designated at a point, along a fault line, or over an area. The sum of each location's distribution is $P=1.0$. Different possible locations of the source mean different attenuation distances.

Performing a PSHA requires a large quantity of data, computing power, good attenuation models (step 2, fig. 2. and fig. 3.), and accurate soil properties for nearsurface site response analysis (step 3, fig. 2.). In evaluating seismic response, the engineer is not limited to a single attenuation model or site response method. One may choose from several models and decide which one should be considered the best, then weigh each model with a percentage that totals 100 (e.g. $50 \%, 35 \%$, and $15 \%$ ). In this 
way, we may consider input from a variety of methods to evaluate the same hazard. Using a logic tree approach, one may use different methods along every step of the way.

At the end of this effort, the design engineer has a quantitative measure of the earthquake hazard expressed as peak acceleration, velocity, displacement or as a spectrum of accelerations, velocities and displacements over a range of frequencies. The spectrum approach is useful since it delivers more information than a single peak value, and it can be compared to building response more directly. The spectra may be used as a means of comparing different candidate earthquakes for more rigorous time history building response analysis discussed later. Additionally, the engineer has some quantification of certainty in the calculations. This is represented by the "spread" of the probability distribution as the computations proceed from source to site. The engineer will also have a better idea where more field, laboratory, or analytical work would do the most good in reducing uncertainty.

\subsection{Building Resilience}

The other side of risk assessment is to determine how resilient the building stock of the examined city may be. Resilience is a combination of strength, stiffness, and ductility which contribute to the performance of a building during an earthquake. One of these quantities alone is not sufficient: a strong building that is not ductile may crack and collapse; a ductile building may sway so much that everything within the structure is destroyed. So the correct combination of these properties, combined with common sense in structural design, will result in very satisfactory performance under seismic loading with only a moderate increase in construction costs. The main component of seismic loading is horizontal. Since buildings are designed to resist vertical forces from gravity, and to a lesser extent wind and ancillary loads applied laterally, the main weakness of most structures is lateral. Horizontal shaking is also stronger than the vertical component. Using an approach similar to evaluating hazards, an engineer may choose from an increasingly complex list of candidates [2]:

1. Apply additional lateral static loading to the structure and compute stresses and deformations to see if they are below maximum criteria.

2. Use additional lateral static load values based on earthquake spectra and the fundamental frequency of the building.

3. Perform a modal analysis to determine the structure's resonant response and apply a better static coefficient for scaling earthquake loads to compute and compare stresses and deflections.

4. Apply an earthquake acceleration history to the base of the structure that represents an expected event and compute stresses and deflections. The structure is modeled as elastic and unyielding. This may sometimes yield unrealistic (too high) stresses on the structure.

5. Push the structure laterally at specific locations until it collapses. Since the analysis is deflection-controlled rather than load-controlled, the structure may soften as it yields. Plastic hinging may take place at several locations and the structure will resist by plastic resilience. This approach, pushover analysis, has become very popular in research and design. 
6. Apply an earthquake history to the base of the structure and determine the nonlinear behavior of the entire structure. Such analyses are preceded by linear methods (4) and require placement of plastic hinges at important locations. This is a computationally intense exercise.

7. Perform an analysis similar to (6) but add the nonlinear behavior of the soil and foundation as well. Of course, this becomes extremely time-consuming.

Performing analyses nr. 5, 6, and 7 require multi-processor workstations or high performance servers. A comprehensive pushover analysis (5) may take 1-2 hours for one realization, while (6) would require several hours. A full SSI analysis with nonlinear materials and large deformations would require an overnight computation. High performance computing will significantly reduce the computation time, but still requires hours of careful evaluation per scenario to insure the results are reasonable and properly represent the problem being studied.

The final result of a building analysis may be a simple failure/no failure decision, a capacity curve which can be matched to a hazard curve, or a range of outcomes and probabilities for a single structure or an entire population of structures. Once the building resilience is determined, it can be compared to the hazard. If the hazard is stronger than resilience, failure is possible; if the building is more resilient, it will remain standing. Of course, this is a simplification. Even with the most basic approaches of using a seismic coefficient to compute added static loading, there are elements of probability that are implied, if not stated.

Most work today is based on extensive probabilistic studies, but simplified for direct use through a prescribed evaluation method. The evaluation may be a listing of building features including sized, shape, regularity, and construction materials. Based on different selections, an estimated building resilience is formulated. The advantage of such a method is speed and low cost for applications to a large population of buildings in a city or town. The disadvantage is that other potentially important building features are ignored and the evaluation method is visual so structural details such as reinforcement schedules and joint details are not known. Bear in mind as well that a numerical model, no matter how sophisticated, will not completely capture the behavior of an actual building as it experiences shaking from an earthquake. While precise behavior is very difficult to predict, general behavior and points of strength and weakness throughout the structure do become clearer. Numerical modeling is still more valuable from insight than precise prediction.

\subsection{Overall Seismic Risk}

The final comparison between hazard and resilience is risk assessment. This not only involves some direct comparison between the level of hazard, i.e. the strength of an anticipated earthquake and structural resilience of the building stock, but also the final outcome of damages and lives lost. Estimating mortality is perhaps the most difficult since there can be so many factors to consider and often little data on which to base estimates. Some of the factors considered in risk assessment are shown in figure 4. such as disaster preparedness, built environment, transportation and communication infrastructure, lifelines, medical readiness, emergency management, economic and 
social standing, cultural traditions, community and familial ties, construction markets, insurance methods, and many other factors.

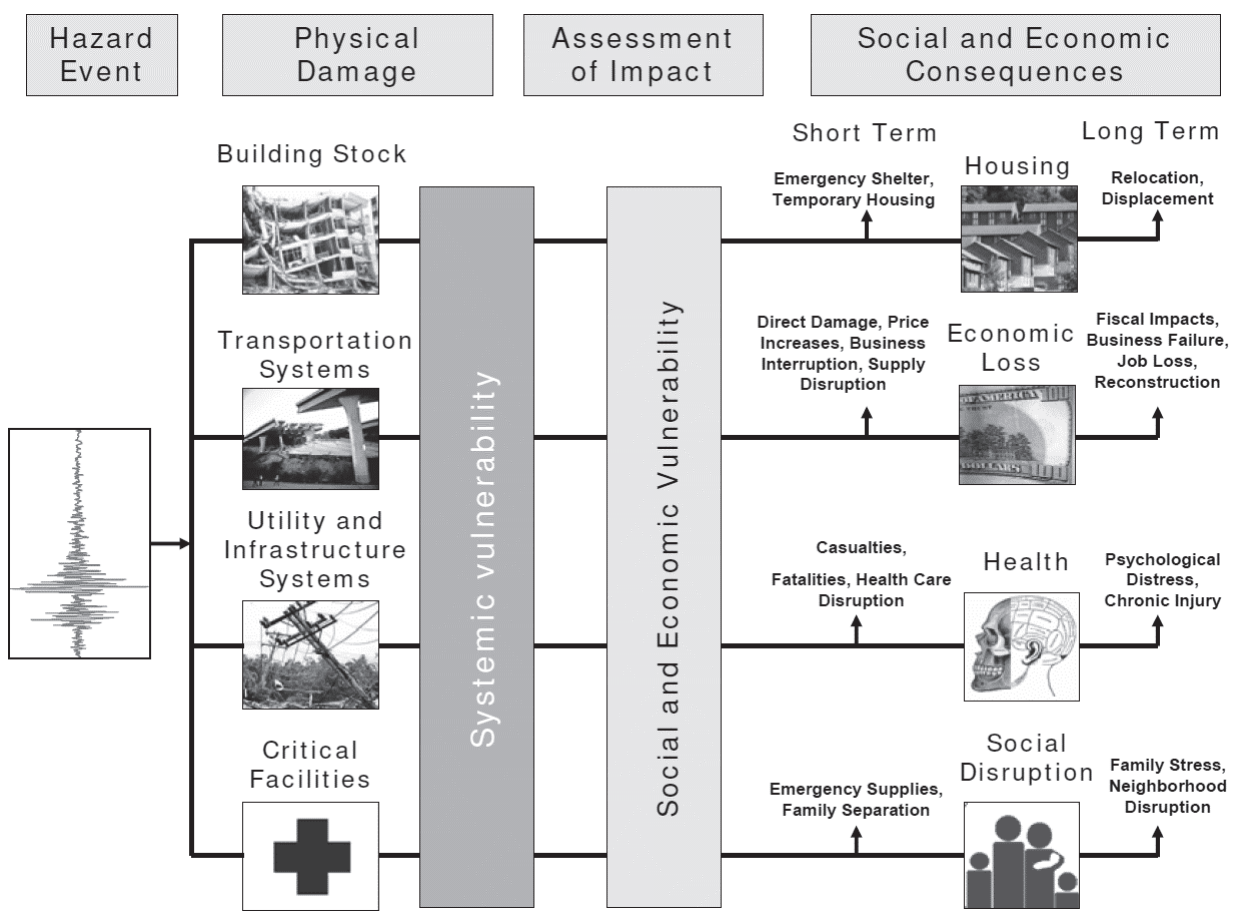

Figure 4. Factors considered in a comprehensive risk assessment [20]

\section{Seismic Risk in Hungary}

In a region of moderate seismic activity, it would be a prudent exercise to determine seismic risk just as one would consider other natural and man-made hazards. While the specific scientific and engineering knowledge is unique to earthquake phenomena, the application of risk assessment and decision-making is not. Incorporating seismic considerations into the building code has already been done. It has forced engineers to consider the possibility of seismic events that they did not have to consider previously. Of course this is not unique to Hungary, and one of the future challenges is to harmonize evaluation of seismic hazards with neighboring countries in order to have a seamless transition across borders.

\subsection{Risk Studies in Hungary}

Seismic hazard assessment dates back to 1960s motivated by industrial and economic development requirements. The first probabilistic seismic hazard map was prepared by Zsíros in 1985 [22]. The basic source for earthquake seismic hazard assessment is the Hungarian Earthquake Catalogue [22]. The current Seismic Hazard Map of Hungary [7] is presented in figure 5. It represents estimated contours of maximum horizontal acceleration in bedrock due to seismic events that have a $10 \%$ probability of occurring 
in 50 years. This probability of occurrence is a standard value used throughout the world and means one event with the given value taking into account a return period of 475 years.

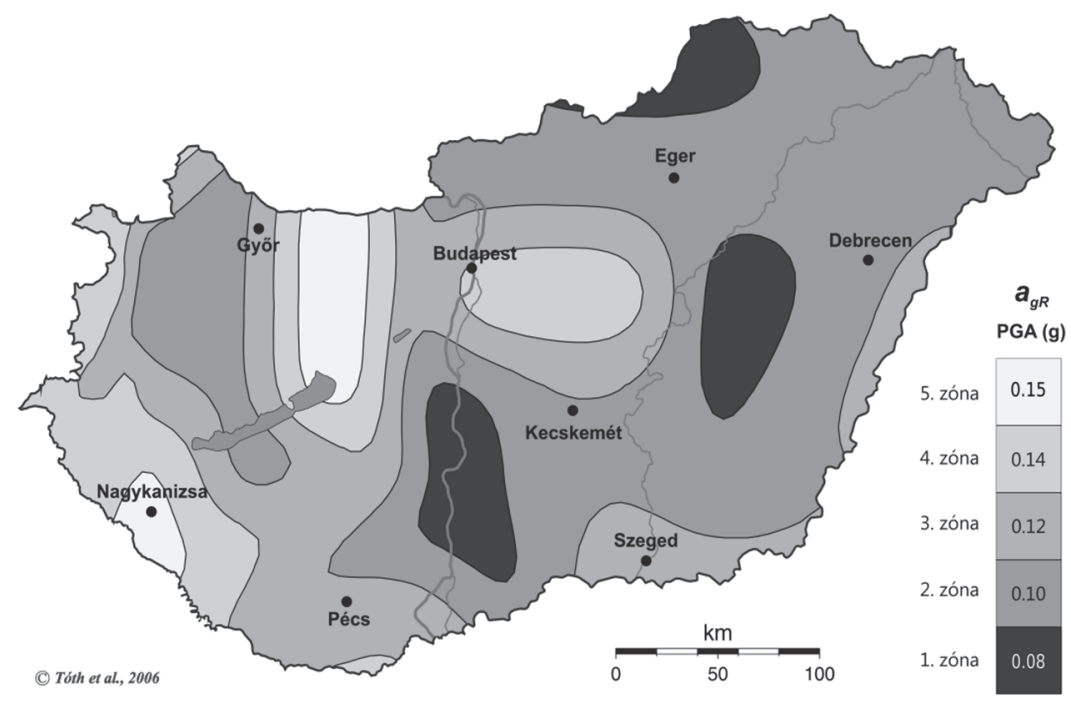

Figure 5. Peak horizontal accelerations from a seismic event that would occur once in 475 years (or a 10\% probability of occurring in 50 years). Values range from $0.08 g$ to $0.15 \mathrm{~g}$. The highest values are located in the north-south line of the Mór trench and the southwest corner around Nagykanizsa. (adapted from Tóth et al, 2006) [7]

Vulnerability assessments were performed in the case of the nuclear power plant in Paks by $\mathrm{T}$. Katona [12]. Other vulnerability assessment studies have been performed concerning typical masonry and RC buildings in the past few years [13, 14].

Risk assessment studies were performed on the downtown Budapest area [8] and Debrecen [9]. It should be noted that these researches were mainly focused on a deterministic seismic hazard assessment combined with an eigenfrequency estimate of the building stock within $0.1 \mathrm{~km} 2$ zones throughout the city. The risk map developed for Debrecen represents a relative degree of damage of the buildings compared to each other.

\subsection{Application of Seismic Risk Analysis to Győr}

The Györ area is considered to be in a moderate earthquake risk zone with past events estimated up to Mm 6.5. It is a typical situation for many cities in Hungary and throughout Europe where the seismic hazard is not great, but cannot be ignored. Based on the [7] Seismic Hazard Map of Hungary the level of ground motion is $0.12 \mathrm{~g}$ PGA at bedrock with $90 \%$ probability of non-exceedance in 50 years (fig. 5.). Magnitude 3 and 4 earthquakes are quite frequent in this region, while magnitude 4 and 5 earthquakes happen every 50 years close to Györ, and every 10 years within $100 \mathrm{~km}$ of the city. The return period of magnitude 5 and 6 events is about 100 years; this correlates with 
hazards determined by Tóth et al. [21] and underlines that the seismicity of the region has been underestimated previously by the County Emergency Directorate.

In order to make the best use of limited resources, this methodology used existing soil data, rapid visual building assessment, a limited number of field tests and free, but sophisticated software [15]. As the area of Györ is at the meeting point of different geological structures, further research concerning the local seismicity and soil conditions were performed in order to differentiate between the very diverse territories of the city.

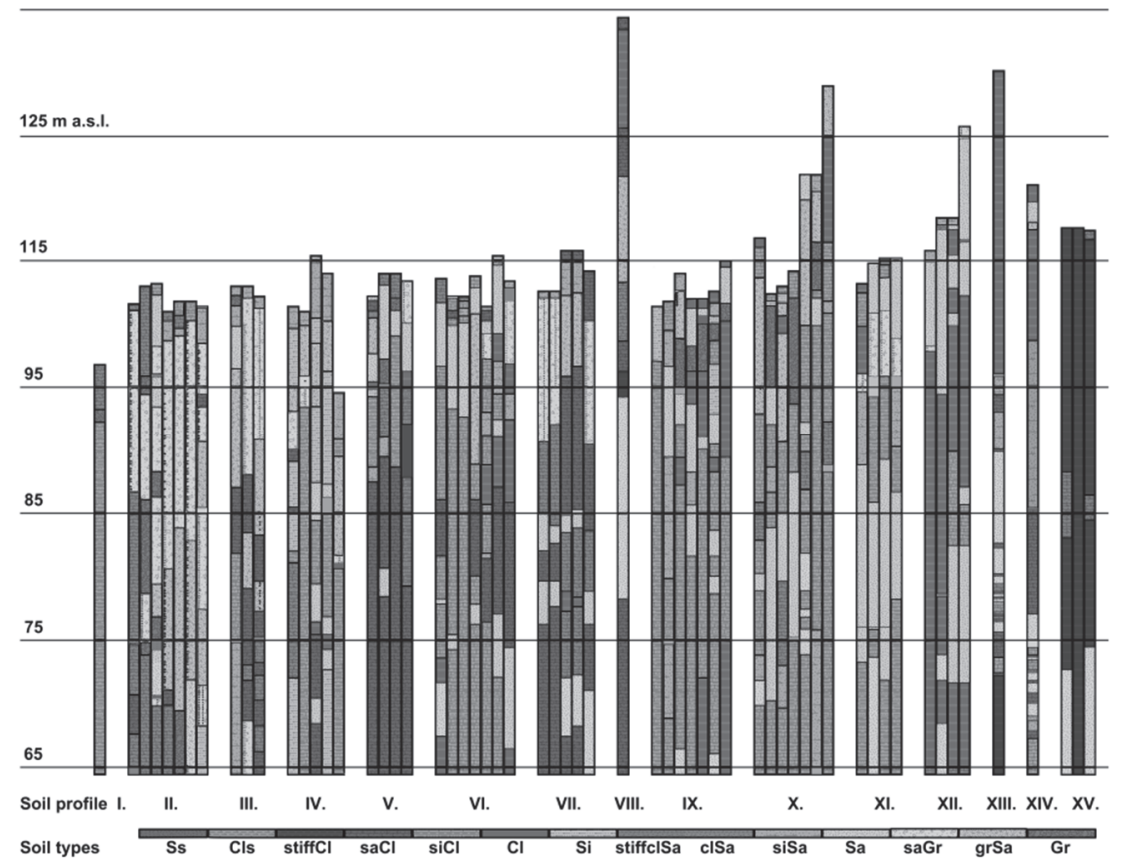

Figure 6. Soil profile groups used to perform detailed site response analyses. Some groups need more data to give a complete picture of that area. [15]

With the permission of the North Transdanubian Environmental Protection and Water Management Inspectorate, soil profiles were collected from the hydrogeological registers. On the territory of the investigated area, around 100 borings were available, from that 60 were picked for further study. The principle of selection was to cover adequately the study area with borings deeper than $30 \mathrm{~m}$. General stratigraphy allowed us to categorize the soils into 15 general profiles as shown in figure 6 . In addition to the boring data, field testing by MASW was performed in strategic locations and a limited number of dynamic CPT tests were also applied. Based on the results and correlations with the historical data, soil profile zones were delineated through the city.

Using the different soil profiles, 1-dimensional site response analyses (STRATA [16]) were performed by applying a suite of 7-10 different earthquake records to the base of the profiles. The records were chosen and scaled to fit the general requirements of this region. Additionally, nonlinear behavior models were applied to the different soil layers, based on our dynamic laboratory test results and correlations to other models. The 
software allowed us to consider reasonable variations in soil properties and thicknesses of layers. In all, 6000 realizations were generated.

The effect of the different soil zones on surface response were evaluated and the results were compared to the more uniform approach described in Eurocode 8 [4]. While there was very general agreement with EC-8, there was also a great deal of variation in the level of seismic action due to the different soil profiles. The different seismic actions could be mapped in a manner similar to the soil profiles. The responses were different enough to divide the city into seven different zones.

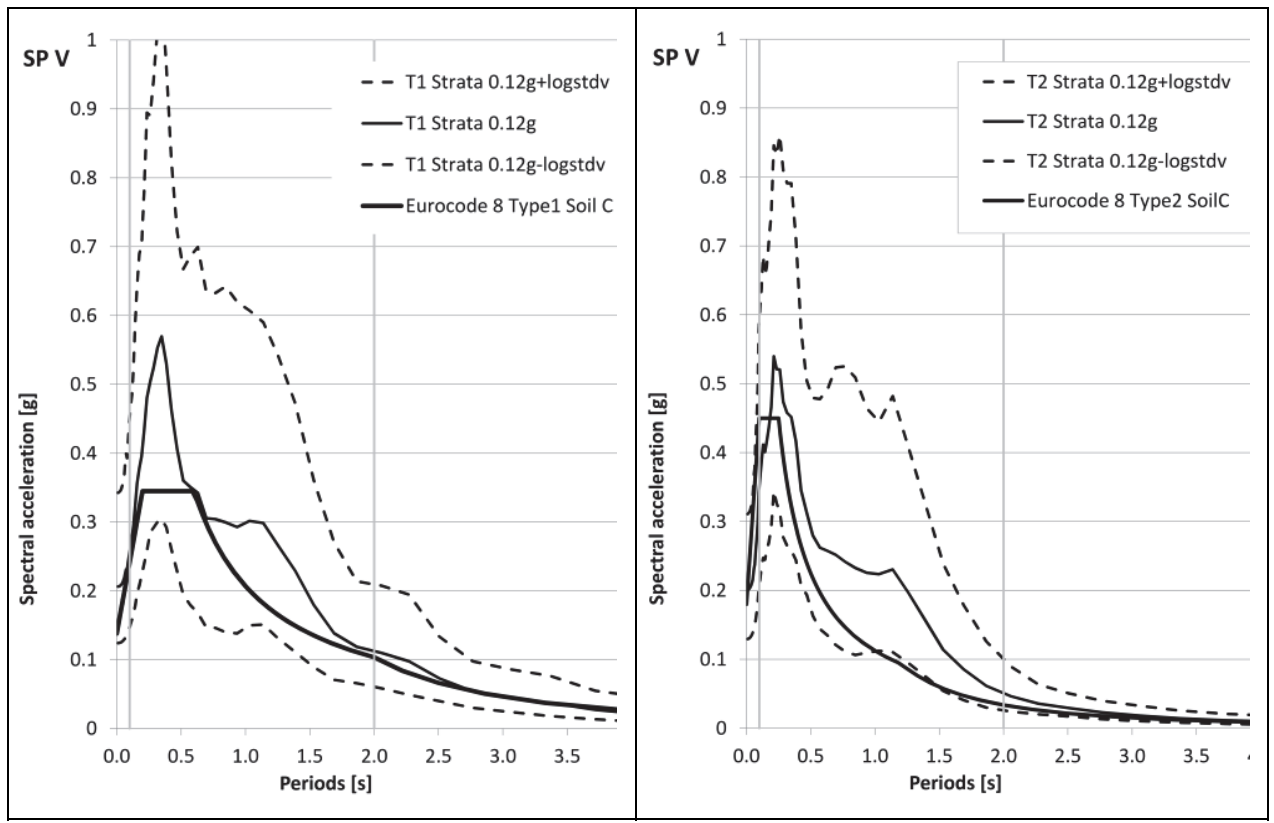

Figure 7. Comparison of average, -1 log standard deviation and +1 log standard deviation results with Eurocode 8 design spectra. Type 1 spectra are shown on the left, Type 2 on the right. The seismic inputs for STRATA matched each Type for comparison.

Soil profile V. is shown in figure 7. where the surface response spectra are shown from the Strata runs. On the left is shown EC-8 Type 1 spectrum for Soil Profile C. Also shown are the average and one log standard deviation spectra from all of the Strata runs performed for this soil profile and using earthquake records that matched Type 1 spectra within a $10-15 \%$ range over most of the frequencies. The same is true for the Type 2 spectra comparisons on the right. The PGA for all analyses was $0.12 \mathrm{~g}$. While the general magnitude and shape of the surface spectra are similar, there are noticeable differences at the peak values for Type 1 and at slightly lower frequencies (longer period). Each figure represents about 100 realizations from Strata. The use of a log normal distribution to describe variability in response spectra is a standard practice. The figures demonstrate the importance of performing site specific analyses if one needs accurate information. Other soil profiles showed similar variation. 
The rapid visual evaluation of buildings was performed on over 5000 structures in Györ. The evaluation method was developed from well-known approaches $[5,6,10]$ but modified to account for typical building designs found here. The reliability of the visual evaluations performed by trained non-experts was verified by experts over a significant percentage of all buildings. Further evaluation of building vulnerability was performed by pushover analyses by simplified methods. The pushover analyses showed that the visual vulnerability assessments were consistent and reasonable. The dominant building type found in Györ is load bearing masonry with some reinforced concrete frame components. While they are generally strong buildings, they possess little ductility and do not perform well under severe shaking. When subjected to moderate shaking they will perform adequately much of the time. Construction methods, material quality geometric regularity, roof mass, and presence or absence of reinforced concrete columns and beams all contribute to the buildings' performance.

In order to determine the vulnerability throughout the city, city districts were divided into sections that each had a high percentage of one or two similar building types. This allowed for an accurate and rapid method to divide the risk assessment into manageable pieces. The evaluation process used about 25 sections within the city.

\section{Number of dominant building structures}

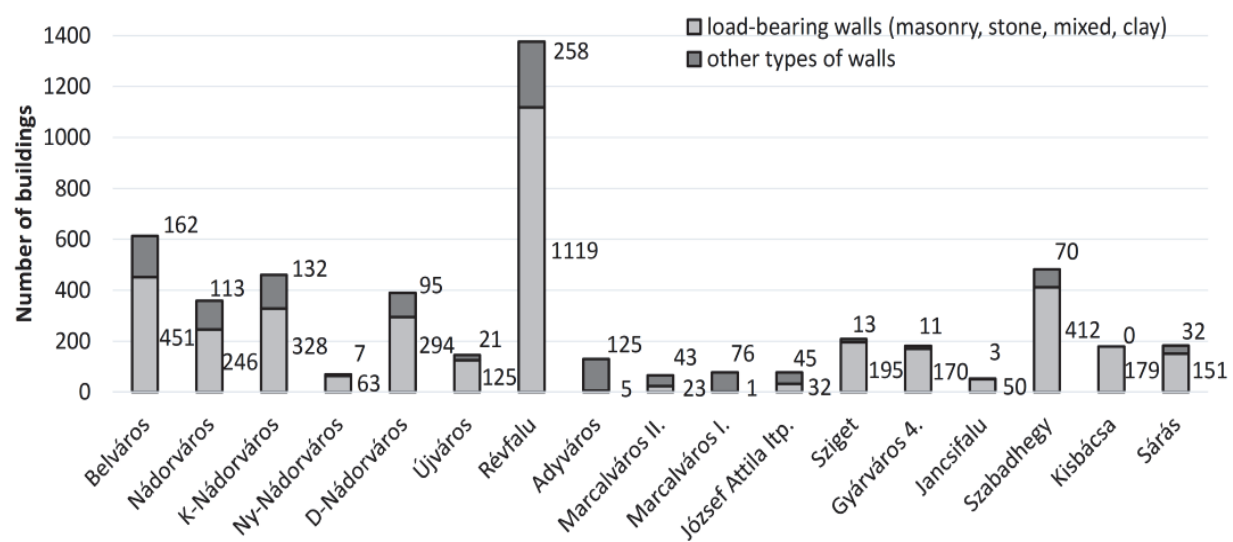

Figure 8. Dominant building types in Györ. Note the very high number of load bearing masonry wall structures.

Estimates of seismic risk were computed using seismic hazard results and building vulnerability scores. As one would expect, since the hazards and vulnerabilities were not uniformly distributed around Györ, there were zones of higher and lower risk. Figure 9. shows the zones that have been delineated. The old downtown area exhibits the highest seismic risk (7) because it has a fairly high hazard level (the site response from its soil profiles were stronger than most) and a high vulnerability (the building stock was generally unreinforced masonry, or combined masonry/concrete load bearing walls). Building geometry was less regular, roofs were generally heavy, and the quality workmanship was highly variable. The industrial park shows the lowest risk (1) because the hazard was moderate; the buildings are modern, framed, reinforced, and regular. Roofs are lighter and workmanship is much more consistent. 


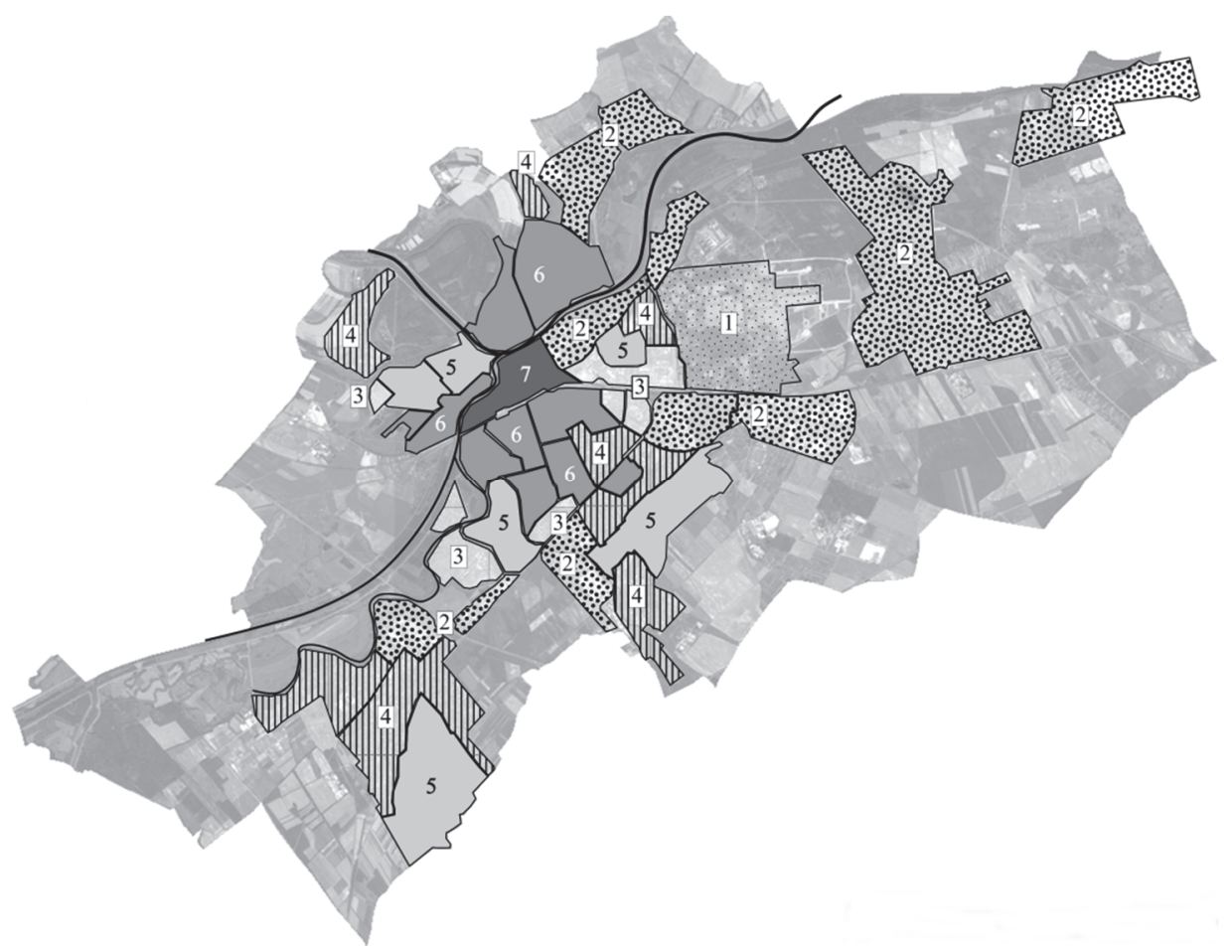

Figure 9. Relative seismic risk zones in Györ. Zone 7 is highest risk, Zone 1 is the lowest. The old downtown area has the highest risk because the buildings are old and the relative hazard is high compared to the other areas.

These risks reflect only the structural vulnerability and do not consider the consequences of damage. For example, the destruction of a factory in the industrial district may have a much greater economic impact than the damage done to a downtown building. If this is true, a higher risk would be assigned to the industrial sector. We did not have the necessary economic data and models necessary to perform such an evaluation, but those models do exist [11].

The risk assessment process for Györ is by no means finished. Thorough seismic evaluation of typical building types found in Györ is an ongoing research effort now at Széchenyi University. Further evaluation of buildings, soil properties, anticipated seismic events, and ways to implement positive changes to the design and construction of buildings in Hungary are all needed to improve the quality of life. The study performed here is a small part of a much greater system of hazard evaluation and risk assessment that Civil Engineers do. It is the logical continuation of building engineering that has evolved since the beginnings of civilization. As engineers we are committed to protecting the public safety when it comes to the design and construction of civil works. The process of risk assessment fits perfectly into this commitment and is part of the evolution of techniques and methods that are used to help people make better decisions about what and where to build. 


\section{Conclusion}

In a region of moderate seismic activity, it would be a prudent exercise to determine seismic risk just as one would consider other natural and man-made hazards. While the specific scientific and engineering knowledge is unique to earthquake phenomena, the application of risk assessment and decision-making is not. Incorporating seismic considerations into the building code has already been done. It has forced engineers to consider the possibility of seismic events that they did not have to consider previously. Of course this is not unique to Hungary, and one of the future challenges is to harmonize evaluation of seismic hazards with neighboring countries in order to have a seamless transition across borders.

Earthquake risk is a public safety issue that requires appropriate risk management measures and means to protect citizens, properties, infrastructure and the built cultural heritage. The aim of a seismic risk analysis is the estimation and the hypothetical, quantitative description of the consequences of seismic events of an investigated area, on a regional or state level. The effects to be predicted are the physical damage to buildings and other facilities. Based on damage patterns, further studies can determine the possible number and type of casualties, the potential economic losses due to the direct cost of damage and to indirect economic impacts (loss of the productive capacity and business interruption), the loss of function in lifelines and critical facilities (such as hospitals, fire stations, communication system, transportation networks, water supply, etc.) and also social, organizational and institutional impacts.

\section{Acknowledgement}

Data processing of the research concerning seismic risk assessment of Györ was supported by the European Union and the State of Hungary, co-financed by the European Social Fund in the framework of TÁMOP 4.2.4. A/2-11-1-2012-0001 'National Excellence Program' (2013/2014).

\section{References}

[1] Boore DM: Can Site Response Be Predicted?, Journal of Earthquake Engineering, Vol. 8, Special Issue 1, pp. 1-41, 2004

[2] Calvi GM et al.: Development of Seismic Vulnerability Assessment Methodologies over the Past 30 Years. ISET Journal of Earthquake Technology, Vol. 43, No. 3, pp. 75-104, 2006

[3] Committee on National Earthquake Resilience: National Earthquake Resilience: Research, Implementation, and Outreach. Washington, D.C.: National Academies Press, 2011

[4] European Committee for Standardization: Eurocode 8: Design of Structures for Earthquake Resistance MSZ EN 1998-1:2004/A1:2013. Brussels: s.n, 2013

[5] FEMA: FEMA 154: Rapid Visual Screening of Buildings for Potential Seismic Hazard. 2002 ed. Washington D.C.: Federal Emergency Management Agency, 1988

[6] FEMA: FEMA 155: SECOND EDITION Rapid Visual Screening of Buildings for Potential Seismic Hazards: Supporting Documentation. 2002 ed. Washington D.C.: Federal Emergency Management Agency, 2002

[7] GeoRisk Earthquake Engineering Ltd.: Seismic Hazard Map of Hungary. Available at: http://georisk.hu/ [Accessed 0305 2014], 2006

[8] Gribovszki K: Földrengések geofizikai és geológiai környezetének valamint Debrecen földrengésveszélyezettségének vizsgálata térinformatikai eszközökkel (Studying the Geophysical and Geological Environment of Earthquakes and Deterministic Seismic Hazard of Debrecen). Sopron: PhD Dissertation - University of West Hungary, 2005 
[9] Gribovszki K, Panza GF: Seismic microzonation with the use of GIS - Case study for Debrecen, Hungary. Acta Geodaetica et Geophysica Hungarica, Vol. 39, No. 4, pp. 177190, 2004

[10] Grünthal G ed: European Macroseismic Scale 1998. Luxembourg: European Seismological Commission, 1998

[11] Holden RL, Bahls D, Real C: Estimating economic losses in the Bay Area from a magnitude 6.9 earthquake, Monthly Labor Review, December, No.130, pp. 16-22, 2007

[12] Katona T: Seismic Safety Evaluation and Enhancement at the Paks Nuclear Power Plant. Ispra, Italy, Nuclear Energy Agency, Committee on the Safety on Nuclear Installations Workshop Proceedings, 2001

[13] Kegyes-Brassai, O.: Evaluation of Building Structures to Obtain Vulnerability Function in Order to Determine Earthquake Risk. Delft, Fifth International PhD Symposium in Civil Engineering, 2004

[14] Kegyes-Brassai O: The Vulnerability Study of Masonry Structures in Hungary. Geneva, First European Conference on Earthquake Engineering and Seismology joint event of the Thirteenth European Conference on Earthquake Engineering, 2006

[15] Kegyes-Brassai OK: Earthquake Hazard Analysis and Building Vulnerability Assessment to Determine the Seismic Risk of Existing Buildings in an Urban Area, PhD dissertation Széchenyi István University, Győr, Hungary, 199 p, (defense: 2014), 2015

[16] Kottke A, Rathje EM: NEEShub - Resources: STRATA. Available at: https://nees.org/resources/strata [Accessed 1012 2013], 2013

[17] Martinez M: CNN: Six things we've learned since 1994 Northridge Earthquake. Available at: http://edition.cnn.com/2014/01/16/us/northridge-earthquake-things-learned/ [Accessed 3004 2014], 2014

[18] Oliveira CS, Campos-Costa A: Overview on Earthquake Hazard Assessment - methods and new trends. In: C. S. Oliveira, A. Roca \& X. Goula, eds. Assessing and Managing Earthquake Risk. Dordrecht, The Netherlands: Springer, pp. 15-47, 2006

[19] Southern California Earthquake Center: A Comparison of the February 28, 2001, Nisqually, Washington, and January 17, 1994, Northridge, California Earthquakes. Available at: http://www.scec.org/news/01news/feature010313.html [Accessed 3004 2014], 2001

[20] SYNER-G: Systemic Seismic Vulnerability and Risk Analysis for Buildings, Lifeline Networks and Infrastructures Safety Gain. 2009-2012. Deliverable 1.1 - SYNER-G work plan Available at: http://www.vce.at/SYNER-G/ [Accessed 2510 2013], 2009

[21] Tóth L, Győri E, Zsíros T: Seismic Hazard in the Pannonian Region. In: N. Pintér, ed. The Adria Microplate: GPS Geodesy, Tectonics and Hazards. Netherlands: Springer, pp. 369384, 2006

[22] Zsíros T: A Kárpát-medence szeizmicitása és földrengés veszélyessége: Magyar földrengés katalógus (456-1995) (The Seismicity and Hazard of Carpathian Basin: Hungarian Earthquake Catalogue). Budapest: MTA FKGG Kutatóintézet, 2000 